\title{
Recurrent Lymphocyte-Rich Classic Hodgkin Lymphoma
}

National Cancer Institute

\section{Source}

National Cancer Institute. Recurrent Lymphocyte-Rich Classic Hodgkin Lymphoma. NCI

Thesaurus. Code C136971.

The reemergence of lymphocyte-rich classic Hodgkin lymphoma after a period of remission. 